\title{
PENGARUH MENGKONSUMSI GULA AREN (Arenga pinnata) SEBELUM OLAHRAGA TERHADAP DAYA TAHAN OTOT
}

\author{
Cecep Muhammad Alawi ${ }^{1}$, Hamidie Ronald Daniel Ray ${ }^{2}$ \\ ${ }^{1}$ Fakultas Pendidikan Olahraga dan Kesehatan, Universitas Pendidikan Indonesia, Bandung, Indonesia, \\ ${ }^{2}$ Fakultas Human Sciences, Universitas Kanazawa, Ishikawa, Jepang
}

\begin{abstract}
Two kinds of carbohydrates that are used with the body as energy, is blood glucose and muscular glycogen. Savings glycogen in muscular is one of the factors that is affecting muscular endurance when physical exercise. The aim of this study is to find out the significant influence of consuming palm sugar to muscular endurance before physical exercise. The method that is used in this study is to experiment with design pretest-posttest control group design. Total of sample of this study is 18 trained mans that is divided into three groups. The first experiment group is given palm sugar that is dissolved in water, the second experiment group is given sugar that is dissolved in water, and the control group is given mineral water. The instrument of this study is used push up test, sit up test, and squat jump test to measures the upper muscular endurance, middle, and bottom. All of the samples have done pretest and posttest in different day. When posttest, all of the sample is consumed beverage based on the treatment 30 minutes before do the posttest. Data analysis by Paired Sample t-test and continued by One Way ANOVA to see the influence and comparison between groups. The result of this study has showed that there is a significant difference, the raising of muscular endurance is proved by the score (sig) $0.00>0.05$, which the highest increasing is the palm sugar group. Therefore, it could be concluded that there is a significant influence of consuming palm sugar to muscular endurance before physical exercise.
\end{abstract}

Keywords: Palm sugar, Prior exercise, Muscular endurance

Korespondensi: Cecep Muhammad Alawi, E-mail:cecepalawi2@gmail.com, ${ }^{1}$ Fakultas Pendidikan Olahraga dan Kesehatan, Universitas Pendidikan Indonesia, Bandung, Jawa Barat, Indonesia. 


\section{PENDAHULUAN}

Dua bentuk karbohidrat yang digunakan tubuh sebagai energi adalah glukosa darah dan glikogen otot. ${ }^{1}$ Glukosa merupakan karbohidrat dalam makanan yang diserap dalam jumlah besar ke dalam darah serta dikonversikan di dalam hati. ${ }^{2}$ Glukosa dalam tubuh dipecah untuk menyediakan energi pada sel atau jaringan dan dapat disimpan sebagai simpanan energi dalam sel, sebagai glikogen. ${ }^{3}$ Waktu untuk menuju kelelahan otot salah satunya ditentukan oleh seberapa banyak cadangan glikogen yang masih mampu diubah menjadi glukosa. Pada akhirnya, glukosa digunakan sebagai energi untuk melakukan aktivitas. ${ }^{4}$ Simpanan glikogen dalam otot merupakan salah satu faktor yang mempengaruhi daya tahan otot pada saat berolahraga. Jika cadangan glikogen dalam otot habis maka daya tahan otot akan menurun dan bisa menyebabkan kelelahan otot. ${ }^{4}$ Sebagai komponen kedua terpenting pada healthrelated fitness, daya tahan otot memiliki manfaat untuk menjaga dan meningkatkan kinerja seseorang dalam melakukan aktivitas sehari-hari. Daya tahan otot tidak hanya penting bagi kinerja atlet baik pada saat latihan ataupun bertanding, tetapi masyarakat umum pun diharapkan mempunyai daya tahan otot yang baik agar dapat melakukan aktivitas hariannya yang selalu berulang setiap harinya. ${ }^{5}$

Banyak cara untuk meningkatkan daya tahan otot, seperti dengan weight training/latihan beban. Banyak penelitian yang setuju bahwa latihan beban dengan rutin penting untuk meningkatkan fungsi optimal tubuh. Beberapa manfaat dari kebiasaan latihan beban yang rutin yang berhubungan dengan daya tahan otot adalah memperbaiki ketahanan selama latihan dan meningkatkan kekuatan otot. ${ }^{6}$ Status gizi juga berhubungan dengan daya tahan otot, pada sebuah penelitian yang dilakukan pada anak-anak dan dewasa di Mozambik menunjukkan bahwa laki-laki maupun perempuan yang mempunyai berat badan berlebih memiliki nilai yang rendah pada hampir semua tes kebugaran. ${ }^{7}$ Selain latihan rutin dan status gizi, pola konsumsi juga berpengaruh dengan daya tahan otot. Beberapa penelitian yang dilakukan untuk mengetahui hubungan asupan karbohidrat dengan ketahanan menyimpulkan bahwa meningkatkan asupan karbohidrat menghasilkan perbaikan yang signifikan dalam kapasitas ketahanan individu yang aktif. ${ }^{8}$

Gula adalah suatu karbohidrat sederhana yang menjadi sumber energi dan komoditi perdagangan utama. Gula paling banyak diperdagangkan dalam bentuk kristal sukrosa padat. Gula digunakan untuk mengubah rasa menjadi manis pada makanan atau minuman. Gula sederhana, seperti glukosa (yang diproduksi dari sukrosa dengan enzim atau hidrolisis asam), menyimpan energi yang akan digunakan oleh sel. Gula adalah suatu karbohidrat sederhana karena dapat larut dalam air dan langsung diserap tubuh untuk diubah menjadi energi. ${ }^{9}$ Gula aren dewasa ini banyak dikonsumsi oleh masyarakat sebagai salah satu bahan pemanis alami yang cukup aman bagi tubuh, selain itu kandungan dalam gula aren cukup penting peranannya untuk membantu memenuhi kebutuhan tubuh akan nutrisi tertentu. Beberapa kandungan mikronutrien dalam gula aren yang baik untuk tubuh adalah thiamine, nicitinic acid, riboflavin, niacin, asborbatic acid, vitamin $\mathrm{C}$, vitamin $\mathrm{B} 12$, vitamin $\mathrm{A}$, vitamin $\mathrm{E}$, asam folat, dan juga garam mineral. ${ }^{10}$ Namun kandungan yang paling tinggi dari gula aren adalah kandungan karbohidrat yang mencapai 95 gram/100 gram nya. ${ }^{11}$ Kandungan karbohidrat yang tinggi dari gula aren mempunyai pengaruh terhadap kemampuan daya tahan pada saat melakukan olahraga. Hasil penelitian yang dilakukan oleh Syaiful di Halu Oleo University menunjukkan bahwa mengkonsumsi gula aren 30 menit sebelum latihan memiliki pengaruh yang signifikan terhadap daya tahan aerobik melalui Harvard Step Test. Lebih jauh lagi, gula aren dapat mengurangi kelelahan otot pada tikus jantan. Sebuah penelitian yang dilakukan Tolaya pada tahun 2012 menunjukkan bahwa tikus jantan yang diberikan gula aren sebelum berenang memiliki ketahanan berenang yang lebih baik dan memberikan efek anti kelelahan otot. Hal ini menunjukkan bahwa mengkonsumsi gula aren sebelum olahraga berpotensi meningkatkan daya tahan otot. ${ }^{12,13}$

Dari hasil penelitian tersebut penulis tertarik untuk melakukan penelitian terhadap mengkonsumsi gula aren sebelum olahraga terhadap daya tahan otot. Karena belum ada yang meneliti tentang pengaruh mengkonsumsi gula aren sebelum olahraga terhadap daya tahan otot.Tujuan dari penelitian ini adalah untuk mengetahui apakah terdapat pengaruh mengkonsumsi gula aren sebelum olahraga terhadap daya tahan otot, mengetahui apakah terdapat pengaruh mengkonsumsi gula pasir sebelum olahraga terhadap daya tahan otot, dan untuk mengetahui manakah yang lebih baik mengkonsumsi gula aren atau gula pasir sebelum olahraga terhadap daya tahan otot. 


\section{METODE PENELITIAN}

Metode penelitian yang dilakukan dalam penelitian ini adalah metode penelitian eksperimendengan desain Pretest-Post-test Control Group Design menggunakan dua macam perlakuan. Populasi yang dipilih dalam penelitian ini adalah 118 atlet PB Mutiara Cardinal Bandung usia 15-18 tahun. Sampel dipilih menggunakan teknik simple random sampling yang diambil secara acak sebanyak 18 orang terlatih yang dibagi menjadi tiga kelompok perlakuan yaitu kelompok eksperimen 1 menggunakan gula aren, kelompok eksperimen 2 menggunakan gula pasir, dan kelompok kontrol menggunakan air putih biasa. Instrumen penelitian menggunakan push up test, sit up test, dan squat jump test yang dilakukan sampel sampai kelelahan untuk mengukur daya tahan otot tubuh bagian atas, tengah, dan bawah. Pretest dan post test dilakukan pada hari yang berbeda, satu hari sebelum melakukan tes sampel diberitahu agar melakukan puasa selama 9 jam (jam 22.00-06.00) agar semua sampel melakukan tes dalam kondisi yang sama. Pemberian gula aren, gula pasir, dan air putih dilakukan 30 menit sebelum sampel melakukan post test. Kelompok eksperimen 1 diberikan gula aren sebanyak 80 gram yang dilarutkan dalam air sebanyak $250 \mathrm{ml}$, kelompok eksperimen 2 diberikan gula pasir sebanyak 75 gram dilarutkan dalam air sebanyak $250 \mathrm{ml}$, dan kelompok kontrol diberikan air putih biasa sebanyak $250 \mathrm{ml}$. Data dianalisis menggunakan paired sample t-test dan ANOVA satu jalur untuk mengetahui pengaruh dan perbandingan pada tiga kelompok sampel. Analisis data menggunakan program Statistical Product for Social Science (SPSS) Seri 16.

\section{HASIL PENELITIAN}

Gambar 1 menunjukkan hasil rata-rata peningkatan push up sesuai perlakuan masingmasing. Dari gambar tersebut dapat dilihat bahwa sampel yang diberi gula aren sebelum melakukan push up menunjukkan peningkatan yang paling tinggi dengan rata-rata peningkatan 3,17 kali. Sampel yang diberi gula pasir sebelum tes push up mengalami penurunan rata-rata $-0,17$, ini dikarenakan beberapa sampel mengalami penurunan jumlah push up pada saat posttest. Sedangkan sampel yang diberi air putih sebelum melakukan push up menunjukkan peningkatan rata-rata 0,33 . Berdasarkan hasil uji statistik menggunakan One Way ANOVA diperoleh nilaisignifikansi 0,014, sehingga dapat ditarik kesimpulan bahwa terdapat perbedaan rata-rata antar kelompok. Tanda asteris bintang menunjukkan bahwa terdapat perbedaan rata-rata antara kelompok gula aren dengan kelompok gula pasir, tanda asteris pagar menunjukkan bahwa terdapat perbedaan rata-rata antara kelompok gula aren dengan kelompok air putih.

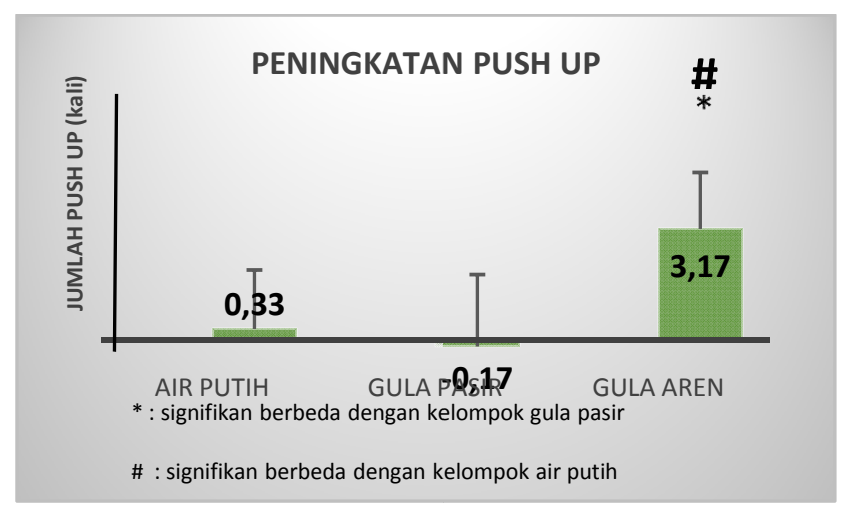

Gambar 1. Jumlah Rata-Rata Peningkatan Push Up Sesuai Perlakuan

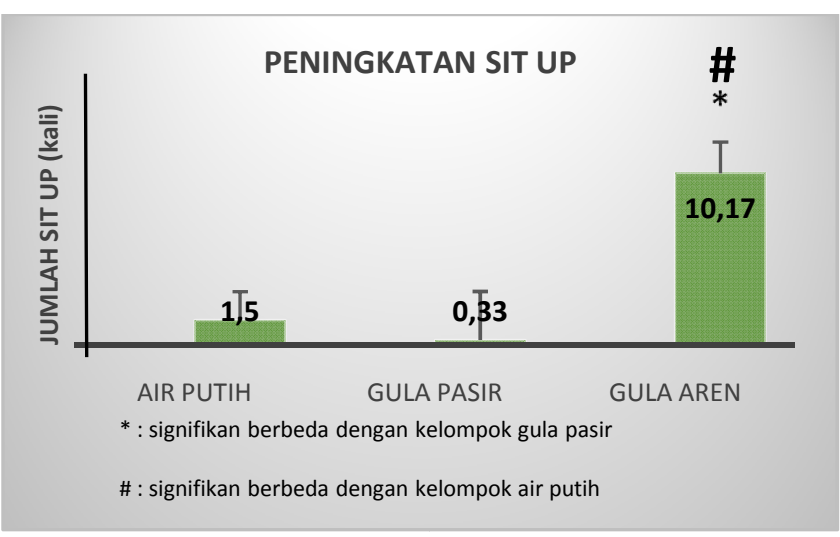

Gambar 2. Jumlah Rata-Rata Peningkatan Sit Up Sesuai Perlakuan

Gambar 2 menunjukkan hasil rata-rata peningkatan sit up sesuai perlakuan masing-masing. Dari gambar tersebut dapat dilihat bahwa sampel yang diberi gula aren sebelum melakukan sit up menunjukkan peningkatan yang paling tinggi dengan rata-rata peningkatan 10,17 kali. Sampel yang diberi gula pasir sebelum tes sit up mengalami peningkatan rata-rata 0,33 . Sedangkan sampel yang diberi air putih sebelum melakukan push up menunjukkan peningkatan rata-rata 1,5. Berdasarkan hasil uji statistik menggunakan One Way ANOVA diperoleh nilai signifikansi 0,00 sehingga dapat ditarik kesimpulan bahwa terdapat perbedaan ratarata antar kelompok. Tanda asteris bintang menunjukkan bahwa terdapat perbedaan rata-rata antara kelompok gula aren dengan kelompok gula pasir, tanda asteris pagar menunjukkan bahwa terdapat perbedaan rata-rata antara kelompok gula aren dengan kelompok air putih. 


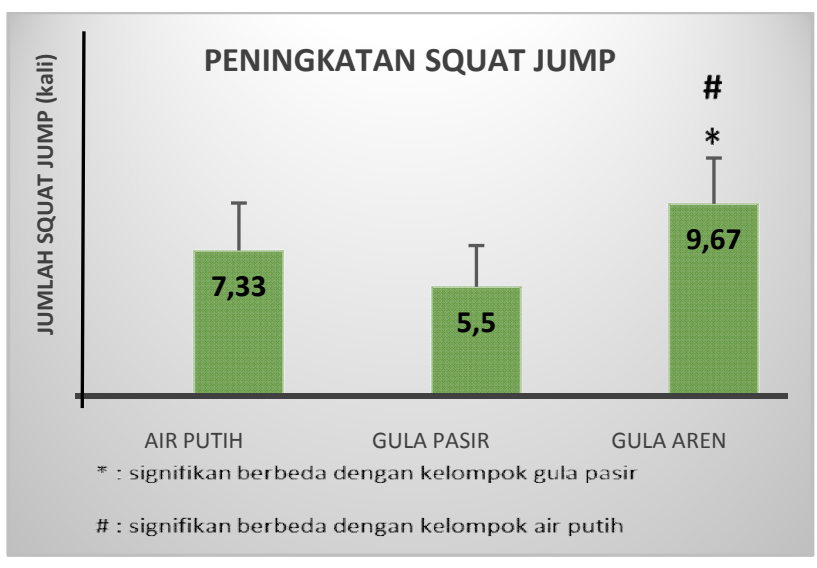

Gambar 3. Jumlah Rata-Rata Peningkatan Squat Jump Sesuai Perlakuan

Gambar 3 menunjukkan hasil rata-rata peningkatan squat jump sesuai perlakuan masingmasing. Dari gambar tersebut dapat dilihat bahwa sampel yang diberi gula aren sebelum melakukan squat jump menunjukkan peningkatan yang paling tinggi dengan rata-rata peningkatan 9,67 kali. Sampel yang diberi gula pasir sebelum tes squat jump mengalami peningkatan rata-rata 5,5. Sedangkan sampel yang diberi air putih sebelum melakukan squat jump menunjukkan peningkatan rata-rata 7,33. Berdasarkan hasil uji statistik menggunakan One Way ANOVA diperoleh nilai signifikansi 0,027 sehingga dapat ditarik kesimpulan bahwa terdapat perbedaan rata-rata antar kelompok. Tanda asteris bintang menunjukkan bahwa terdapat perbedaan rata-rata antara kelompok gula aren dengan kelompok gula pasir, tanda asteris pagar menunjukkan bahwa terdapat perbedaan rata-rata antara kelompok gula aren dengan kelompok air putih.

Gambar 4 menunjukkan hasil rata-rata peningkatan daya tahan otot total seluruh tubuh sesuai perlakuan masing-masing. Dari gambar tersebut dapat dilihat bahwa sampel yang diberi gula aren sebelum melakukan tes menunjukkan peningkatan yang paling tinggi dengan rata-rata peningkatan 23 kali. Sampel yang diberi gula pasir sebelum melakukan tes mengalami peningkatan rata-rata 5,67 kali. Sedangkan sampel yang diberi air putih sebelum tes menunjukkan peningkatan ratarata 9,17 kali. Berdasarkan hasil uji statistik menggunakan One Way ANOVA diperoleh nilai signifikansi 0,00 sehingga dapat ditarik kesimpulan bahwa terdapat perbedaan rata-rata antar kelompok. Tanda asteris bintang menunjukkan bahwa terdapat perbedaan rata-rata antara kelompok gula aren dengan kelompok gula pasir, tanda asteris pagar menunjukkan bahwa terdapat perbedaan rata-rata antara kelompok gula aren dengan kelompok air putih.

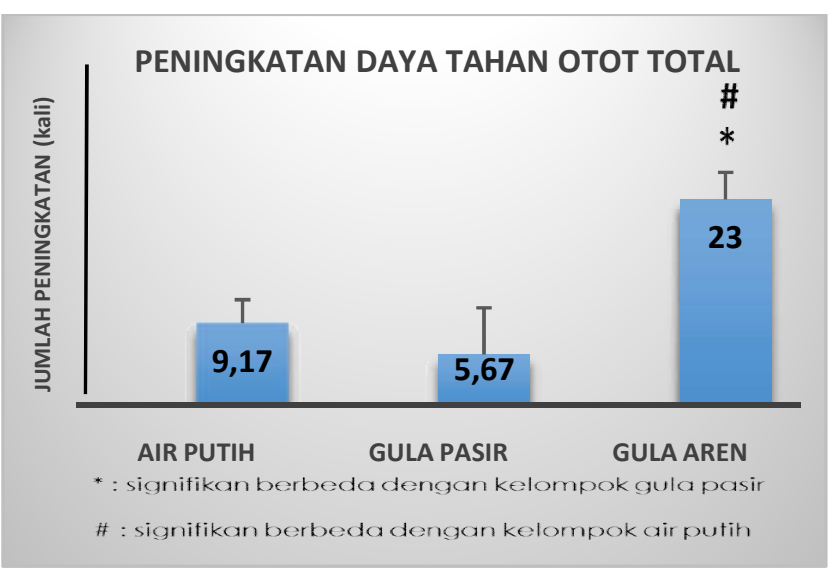

Gambar 4. Jumlah Rata-Rata Peningkatan Daya Tahan Otot Total Sesuai Perlakuan

\section{DISKUSI}

Dari hasil penelitian diatas dapat disimpulkan bahwa terdapat pengaruh yang signifikan mengkonsumsi gula aren sebelum olahraga terhadap daya tahan otot, dan tidak terdapat pengaruh yang signifikan mengkonsumsi gula pasir sebelum olahraga terhadap daya tahan otot. Sehingga dapat dikatakan bahwa mengkonsumsi gula aren sebelum olahraga lebih baik daripada mengkonsumsi gula pasir terhadap daya tahan otot. Peningkatan yang tinggi dari pemberian gula aren sebelum olahraga disebabkan oleh zat nutrisi yang terkandung dalam gula aren, khususnya karbohidrat yang diubah menjadi glukosa dan menjadi sumber energi untuk memungkinkan otot bekerja optimal. Hal ini sesuai dengan pernyataan Pocock, bahwa glukosa dalam tubuh dipecah untuk menyediakan energi pada sel atau jaringan dan dapat disimpan sebagai simpanan energi dalam sel. Karbohidrat dalam bentuk glukosa adalah bahan bakar yang lebih disukai untuk kerja otot. Pada saat berolahraga terutama olahraga dengan intensitas moderat-tinggi, kebutuhan energi bagi tubuh dapat terpenuhi melalui simpanan glikogen, terutama glikogen otot serta melalui simpanan glukosa yang terdapat di dalam aliran darah dimana ketersediaan glukosa di dalam aliran darah ini dapat dibantu oleh glikogen hati agar levelnya tetap berada pada keadaan normal. ${ }^{3}$

Glikogen merupakan simpanan karbohidrat dalam bentuk glukosa di dalam tubuh yang berfungsi sebagai salah satu sumber energi. Terbentuk dari mokekul glukosa yang saling mengikat dan membentuk molekul yang lebih kompleks, simpanan glikogen memiliki fungsi sebagai sumber energi tidak hanya bagi kerja otot namun juga merupakan sumber energi bagi sistem 
pusat syaraf dan otak. Di dalam tubuh, jaringan otot dan hati merupakan dua kompartemen utama yang digunakan oleh tubuh untuk menyimpan glikogen. Pada jaringan otot, glikogen akan memberikan kontribusi sekitar $1 \%$ dari total massa otot sedangkan di dalam hati glikogen akan memberikan kontribusi sekitar $8-10 \%$ dari total massa hati. Walaupun memiliki persentase yang lebih kecil namun secara total jaringan otot memiliki jumlah glikogen 2 kali lebih besar di bandingkan dengan glikogen hati. Pada jaringan otot, glukosa yang tersimpan dalam bentuk glikogen dapat digunakan secara langsung oleh otot tersebut untuk menghasilkan energi. Begitu juga dengan hati yang dapat mengeluarkan glukosa apabila dibutuhkan untuk memproduksi energi di dalam tubuh. Selain itu glikogen hati juga mempunyai peranan yang penting dalam menjaga kesehatan tubuh yaitu berfungsi untuk menjaga level glukosa darah. Sebagai sumber energi simpanan glikogen yang terdapat di dalam tubuh secara langsung akan mempengaruhi kapasitas atau performa seorang atlet saat menjalani program latihan ataupun juga saat pertandingan. Secara garis besar hubungan antara konsumsi karbohidrat, simpanan glikogen dan performa olahraga adalah konsumsi karbohidrat yang tinggi akan meningkatkan simpanan glikogen tubuh dan semakin tinggi simpanan glikogen maka kemampuan tubuh untuk melakukan aktivitas fisik juga akan semakin meningkat. Perlu diketahui bahwa bila otot tidak memiliki karbohidrat maka otot tidak mungkin dapat menghasilkan daya secara anaerobik untuk memenuhi tuntutan beban kerja. Proses pembakaran 1 gram karbohidrat akan menghasilkan energi sebesar 4 kkal. Walaupun nilai ini relatif lebih kecil jika dibandingkan dengan energi hasil pembakaran lemak, namun proses metabolisme energi karbohidrat akan mampu untuk menghasilkan ATP (molekul dasar pembentuk energi) dengan kuantitas yang lebih besar serta dengan laju yang lebih cepat jika dibandingkan dengan pembakaran lemak. Kandungan karbohidrat sederhana pada gula aren merupakan energi yang mudah tersedia dalam waktu singkat sehingga kebutuhan energi secara cepat dapat tersedia untuk metabolisme. Selain itu, gula aren mengandung zat baik lainnya seperti zat antioksidan, tiamin, riboflavin, dan vitamin C. Beberapa zat ini dibutuhkan untuk mengoptimalkan sistem otot dan kardiorespirasi juga daya tahan tubuh kita.

Meskipun memiliki kandungan yang sama yaitu karbohidrat dalam gula aren maupun gula pasir, namun terdapat perbedaan dalam pemecahan menjadi energi di dalam tubuh. Dalam satu hari pankreas yang normal mampu mengubah 90 gram gula aren menjadi energi, sedangkan pada gula pasir pankreas hanya mampu mengubah 5 gram gula pasir menjadi energi. Hal ini bisa terjadi karena untuk mengubah gula pasir menjadi gula darah, tubuh hanya memerlukan waktu 3 menit, tetapi untuk mengubah gula darah menjadi energi yang dapat disimpan dalam otot, pankreas memerlukan waktu kira-kira 140 menit. Pada proses pembuatannya, gula pasir dipanaskan sampai dengan 400 derajat Celcius, semakin tinggi proses pemanasan makanan maka akan sulit dicerna. Dalam satu hari, pankreas yang normal hanya mampu mengubah 5 gram gula pasir menjadi energi, sisa gula pasir yang tidak bisa diproses oleh pankreas akan tertimbun dalam tubuh menjadi gula darah dan lemak. ${ }^{14}$

\section{KESIMPULAN}

Hasil dari penelitian dapat disimpulkan bahwa pemberian gula aren memiliki peningkatan daya tahan otot yang paling tinggi.

\section{DAFTAR PUSTAKA}

1. Fox EL, Bowers RW, and Foss ML.The Physiological Basic of Exercise and Sport ( $5^{\text {th }}$ ed. $)$ 1993. USA: Wim. C. Brown Publisher, pp 16-21, 69, 164,177, 178, 597.

2. Mayes PA, Murray RK, Granner DK. Harper's Biochemistry, 25th edition, 2000. New York : McGraw-Hill, pp 7, 8, 10.

3. Pocock G, Richard CD. Human Physiology The Basic of Medicine, Second Edition. 2004. New York : Oxford University Press, pp 11.

4. Foster, C., Costill, D.L., \& Fink, M.J. Effects of preexercise feeding on endurance performance. 1979. Medicine \& Science in Sports.

5. Hoeger, Werner and Sharon A Hoeger. Fitness and Wellness. 1996. Colorado, USA : Morton Publishing Company.

6. Astrand, Per Olof. Physical Activity and Fitness. American Journal of Clinical Nutrition 55. 1992; 1231S-6S.

7. Prista, et. al. Antropometric Indicators of Nutritional Status: Implications For Fitness, Activity, And Health In School-age Children And Adolescents From Maputo, Mozambique. Am J Clin Nutr. 2003; 77;952-9.

8. Williams, Clyde. Diet And Endurance Fitness. Am J Clin Nutr.1989:49:1077-83.

9. Darwin Philips. Menikmati Gula Tanpa Rasa Takut. 2013. Perpustakaan Nasional: Sinar Ilmu. 
10. Sintia Al. Gula Pasir Versus Gula Aren. 2011. Radar Bandung. Bandung

11. Sunanto H. Aren Budidaya dan Multiguna. 1993. Kanisius. Yogyakarta.

12. Syaiful, H. The Effect of Palm Sugar Concentration Consumed 30 Minutes Prior to Exercise on Aerobic Endurance. (Skripsi). 2013. Teacher TrainingFaculty, Universitas Halu Oleo, Kendari.
13. Tolaya, NM. Uji Anti Lelah Gula Aren dengan Metode Ketahanan berenang Terhadap Mencit Jantan. (Skripsi). 2012. Universitas Ahmad Dahlan, Yogyakarta.

14. Affifah. Perbedaan Gula Pasir, Gula Batu dan Gula Merah. 2016. (Forum Online). Diakses dari https://id.linkedin.com/pulse/perbedaangula-pasir-batu-dan-merah-hendar-toha rumapea. 